\title{
The Study and Practice of the Combined Teaching Mode in Sports Teaching in Colleges
}

\author{
Yong Jia, Chunlei Yuan \\ Foreign Trade and Business College of Chongqing Normal University, Chongqing, China \\ Email:cqrjiayong@163.com
}

How to cite this paper: Jia, Y., \& Yuan, C. L. (2017). The Study and Practice of the Combined Teaching Mode in Sports Teaching in Colleges. Advances in Physical Education, 7, 123-129. https://doi.org/10.4236/ape.2017.72011

Received: January 11, 2017

Accepted: April 4, 2017

Published: April 7, 2017

Copyright $\odot 2017$ by authors and Scientific Research Publishing Inc. This work is licensed under the Creative Commons Attribution International License (CC BY 4.0).

http://creativecommons.org/licenses/by/4.0/

\begin{abstract}
Based on the related statistics about the national physical fitness tests and by looking through related document, the essay analyzes the reasons that influence the decline of students' physical fitness. It also puts forward the combined teaching method, further analyses the validity of the current teaching method based on the actual situation of our school, and publishes a complete set of teaching materials, then combines sports with teaching, enhance afterclass training and scientific research to motivate students' interest of exercise, and to achieve the whole of improvement of students' physical fitness.
\end{abstract}

\section{Keywords}

Physical Fitness, Combined Teaching Mode, Practice

\section{Brief Introduction of the Essay}

Since the national physical fitness test in 2002, a constant decline of Students' physical fitness has been found year after year. Recently, various teaching methods have ultimately aimed at one point-the improvement of students' physical fitness. The study aims at the reform of teaching mode, revising related teaching material, deepening scientific study, extending after-class training so as to achieve the aims of increasing students' interests in sports and strengthening their physical fitness.

\section{Analysis of Students' Physical Condition}

Physical shape is an outer criterion that reveals a student's growth level, generally reflected by length, girth, weight and mutual relation. As can be seen from the documents, college students generally tend to be medium build contrast to the former slim type. However, there still exist serious extremes that either the fat groups are too fat, or the thin ones are too thin. What's more, an apparent in- 
crease in overweight and obesity among college students also emerge into our horizon. It is just these two phenomena that has become a non-neglectful and essential health problem. During the four years' life in college, the rate of overweight and obesity tends to decline in sophomore year, but it is just temporary, and it will further worsen after a certain period until it reaches $11.8 \%$. A test in 2005 revealed that obesity rate among college students in 2000 was higher than that in 1995, and it keeps on the rise (Wang, 2015).

VC index (vital capacity index): Vital capacity is one of the basic factors that measure physical fitness and the competence of constant work, laying an influence on the assessment of college student's physical fitness. Physical fitness includes speed, endurance, outburst, strength, and toughness. As can be seen in documents in 2002, students' physical fitness tends to further decline, and distinctive features of decline rate appear in different items. Compared with the statistics in 2000, the speed (50 m-run) recedes among $87 \%$ age group. Outburst quality (still jump) tends to decline wholly, and endurance among urban and rural men between 19 and 22 declines to $11.9 \mathrm{~s}, 9.7 \mathrm{~s}$, respectively in 1000 meters-run, while women with $9.2 \mathrm{~s}, 9.8 \mathrm{~s}$ respectively in 800 meters-run (Sun, Xia, \& Shen, 2007).

It is also true of Chongqing college students. There exist apparent changes in physical fitness among students in the year of 1995 and 2005. Vital capacity index declines with a daunting speed. The average vital capacity of men and women is lower than that of the whole nation. Their physical fitness in bounce (still jump) appears to turn for the better, while speed (50 meters-run), endurance (man 1000 meters-run, woman 800 meters-run)and outburst (throw solid ball) tend to decline (Song et al., 2006).

As can be seen from the above, great changes in physical shape have arisen among college students. Vital capacity and weight also decline, the most salient one is the endurance. The unbalance of shape, capacity and quality mainly results from their lack of enough sports exercises.

\section{Reasons Accounting for the Physical Fitness Problems}

As for the reasons accounting for the decline of students' physical fitness, a few experts, scholars and officials has drawn convincing conclusions from different sides.

1) There are seven factors given by Li Yongliang-a famous expert in sports teaching:

a) Normal sports time is squeezed out, resulting in students' lacking effective sports exercises.

b) The unrealistic pursuit of college enrollment leads to students' burden with little leisure time and less sports time.

c) Teachers' quality is low, which results to the lack of quality in sports and effectiveness.

d) Lack of enough sleeping time.

e) School's extreme lack of financial investment in sports including sports 
fields and equipment.

f) The irrationality and unbalance of nutrition of students' food.

g) Poor systematic sports policy and regulation leads to students' lack of sports guarantee. While there is also opinion that the leading "murder" lies in different kinds of schools, most of which are unable to complete the sports tasks according to the related regulations, and their very leading aim is to pursue enrollment under uncompleted thinking. Led by this conception, some schools neglect related curriculum regulations, occupying much of sports time or don't arrange sports classes, which directly leads to the constant decline of students' physical fitness. This view deems that the schools should assume the responsibility of the decline of students' physical fitness all over the nationwide (Li, 2007).

2) Zhang Guosheng deems that the reasons are as following:

a) There are not enough sports exercises, especially for the students living in cities.

b)The influence of the exam-oriented education with one-sided pursuit of enrollment by imposing more school work burden and longer study time, less time for students' engaging in sports exercises.

c) Parents' over attention on study and on the development of their physical fitness.

d) Teenagers' blind pursuit of the beauty that the more slim, the more beautiful, thus the health problem of malnutrition led by dieting to lose weight overflows among the public..

e) The increasing popularity of computer games attributes to great changes in the young generation's lifestyle and their ways of entertainments. In this way many students tend to refuse to go out on weekends and on vacations, neither are they willing to participate in sports activities (Zhang Guosheng).

3) Environmental factors:

a) Lack of social publicity of the awareness of sports. As we know, various TV Programs are almost concerned with entertainments, neglecting the silent transforming influence on the adolescents. Spontaneously, they prefer to staying at home enjoying the TV shows or playing tempting computer games.

b) Unhealthy lifestyle from family. An athletic atmosphere is also an important factor. As parents are the good examples for their children. They generally point to one side-lack of enough exercises (Zhang Guosheng).

\section{Measures to Student's Physical Fitness Decline}

1) Assess the validity of current teaching method. The validity of teaching method directly influences students' master of knowledge and their practice. In the study, the sub-object of the national object "the validity study of teaching method", mainly carries out the analyses of various teaching method, thus achieving the complementation of different teaching method.

2) Learn and use the experience of combined teaching mode. As is conveyed by the study, campus sports curriculum appear such situations that either teachers occupy more time than students, or students' free practice without enough 
teachers' instruction. Certain improvement should be made into current teaching mode while in the process of using combined teaching mode. What's more, implement five-step (question-practice-answer-explain-practice) teaching mode to lead to students' initiative of thinking, finding solutions, and carrying out rational exercises under the instruction of the teachers, which can wholly improve students' interests of exploring their potentials. This study has obtained the admission of the study of higher education reform and has completed related research.

3) Summarize the problems and useful solutions in the process of teaching, collect all the problems and then work out a comprehensive material "teaching notes" as references for later teaching practices and application. Up to now, a treatise called "teaching notes" has been published to the public.

4) Publish related teaching materials to promote students' initiative of exercises and reach the goal of improving students' physical fitness. "College sports" has been published with different parts. On the one hand, it provides necessary reference, on the other hand, it also provide related text and pictures as an aid for students' learning.

5) Apply for extended objects to enrich teaching achievements with constant scientific research. After the complement of related study, some related study will be introduced into teaching activities so as to make sure that the teaching process successfully continue and make better achievements. Reflect, summarize, work out a rational thinking mode based on former reflection, find out the teaching and researching problems that needed to be extended, then come up with new thought, apply for new teaching reform set up new scientific research project and enrich the connotation of achievements based on the reference of our outstanding predecessor (Lu \& Yuan, 2006).

6) Reinforce after-class training and activate the exercising atmosphere by the power of good examples. After-class training is an extension of class teaching. Assemble superior students in the class, and give them systematic training, expect them to reach higher standard, which ultimately will incarnate the feasibility of the teaching mode. These superior students will facilitate the initiative of surrounding partners to engage in sports exercises, thus gradually forming a good atmosphere of exercises with everyone embracing a harmonious and energetic studying and living environment.

\section{Suggestion-Combined Teaching Mode}

Based on the measures mentioned above, to improve students' physical fitness focus more on a scientific teaching mode in the whole, which can further make up for the deficiency of the old teaching method. That is-Combined Teaching Mode. The Combined Teaching Mode refers to the combination of demonstrating method, seeking and learning method, discussing method, question and answer method; transform the three-step teaching method to a five-step one, that is: "teacher's explaining-student's exercise-correcting mistakes-consolidating" to "teacher's raising the question (question)-student's thinking and practicing 
(practice)-student's answering the question (answer) - teacher's teaching and responding (teaching) - consolidating and correcting mistakes (practice)", which can gradually exploit students' competence of thinking, communicating, expressing and exchanging and also help students form an awareness of innovation (Figure 1 \& Figure 2), the whole of which will contribute to a realistic and feasible teaching mode in a large extent (General Office of CPC Committee and State Council, 2007).

Figure 1 is the scheme of traditional teaching mode, which is divided into two progresses. In the learning progress, students have little idea of a sport event at the beginning, and then they gradually come to form certain awareness and skills under the teacher' command. As a teacher in the teaching process, they often play the role of demonstrating certain actions. Based on their former awareness, the student model and practice a series of actions as the teacher do and the teacher, in turn, corrects their wrong point.

Figure 2 is referred to as the scheme of the Combined Teaching Mode that is unique of its students-centered feature. As can be seen from the figure, it comes with one more process-the acquainting process, which gives allow students to have more time to get familiar with a certain event by their own frequent practice. In return, it is bound to promote students' initiative of thinking, expressing, communicating skills. Furthermore, it will deepen students' understanding of a sport event.

\section{Analysis of Evidence}

What is unique about the Combined Teaching Mode is that it attaches more importance to students' perception phase. What's more, it focuses on giving students more thinking space while in the phase of question, practice, answer and explanation. The first step "raise the question" and the second step "group

Learning process: ignorance $\longrightarrow$ awareness $\longrightarrow$ application

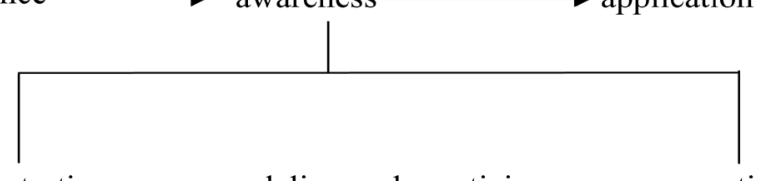

Teaching process: demonstrating $\longrightarrow$ modeling and practicing $\longrightarrow$ correcting

Figure 1. The scheme of traditional teaching mode.

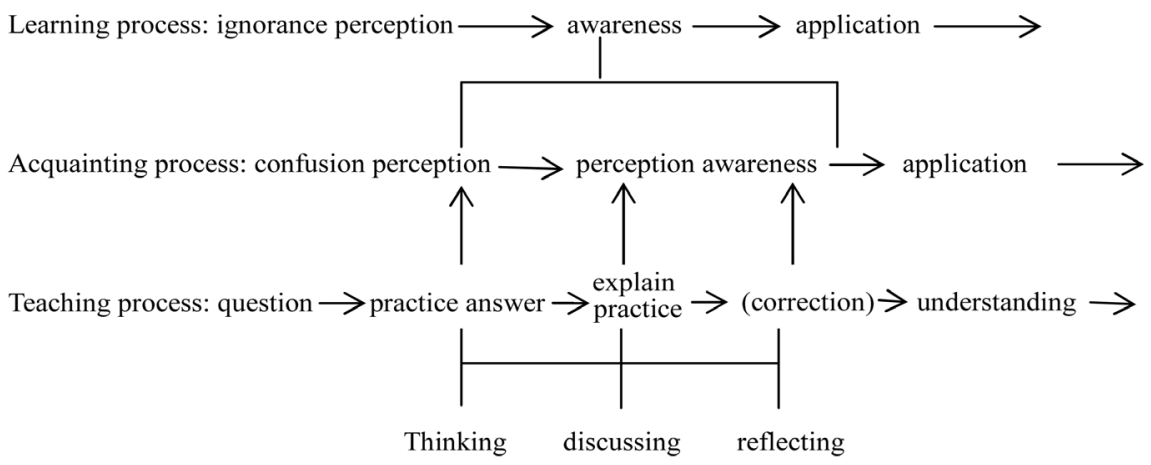

Figure 2. The scheme of combined teaching mode. 
Table 1. Physical fitness test on college students in Chongqing.

\begin{tabular}{ccccc}
\hline & $\begin{array}{c}50 \text { m-run (average } \pm \\
\text { standard deviation) }\end{array}$ & $\begin{array}{c}800 \mathrm{~m} \text {-run } \\
\text { (average } \pm \text { standard } \\
\text { deviation) }\end{array}$ & $\begin{array}{c}1000 \mathrm{~m} \text {-run } \\
\text { (average } \pm \text { standard } \\
\text { deviation) }\end{array}$ & Passing rate \\
\hline 2015 & $8.50 \pm 0.60$ & $4.12 \pm 0.17$ & $4.21 \pm 0.32$ & $83.15 \%$ \\
2014 & $8.68 \pm 0.87$ & $4.17 \pm 0.36$ & $4.24 \pm 0.87$ & $78.68 \%$ \\
2013 & $8.91 \pm 1.02$ & $4.25 \pm 0.48$ & $4.29 \pm 0.58$ & $77.32 \%$ \\
\hline
\end{tabular}

practice" enable students to have more time to think, in which process students can also discuss with their partner, and an initiative of thinking, expressing and communicating can gradually emerge (Figure 2), in return, making a profound and positive influence to student's thinking development, exploring spirit, expressing competence, etc. (General Office of CPC Committee and State Council, 2007).

In the process of demonstrating, group discussing, students can reflect on their own practice method, such as "whether my own method is proper, yes or no?", in this way, students will think actively, thus, facilitating their thinking development, helping form the mind of exploring and innovating.

\section{Achievements}

1) Thanks to several years' well-grounded comprehensive practices through Combined Teaching Mode, there appear certain improvements in students' physical fitness conditions. According to physical fitness test, the endurance appears to rise every year, as revealed in Table 1.

Table 1 is the physical fitness test of college students in Chongqing, as is shown vividly to us, students' running score has annually appeared sound since 2013, and the passing rate has also risen gradually.

Combined teaching mode has won wide popularity among students, which breaks through the former rigid teaching mode that seriously smothers students' interests in sports (Liu, 2006). To make things better, their initiatives of engaging themselves in sports have risen apparently. There are also some students to sign up for memberships in gyms during their spare time. And the quantity of individuals exercising along Binjiang Road has also appeared to rise.

Based on the validity of the Combined Teaching Mode, a school basketball team with the conception of proper combination of sports-teaching has been formed. Compared with the former team that is without comprehensive regulations (Liu, 2006), the new team has successfully applied the theory to useful practice. In the last three years, with constant improvement, our school basketball team has drawn useful lesson from former shortcomings and has ranked the second in 2015 on the base of the former sixth in 2013 in Chongqing, which has helped improve the teaching image of our school.

The teaching material "College Sports", has been subscribed and put into use by Chongqing College of Humanities, Science and Technology, which can demonstrate our quality and level of the books we wrote. 


\section{References}

CPC (2007). Central Committee and State Council's Proposals on Reinforcing Adolescent's Sports Exercise and Strengthening Their Physical Fitness. General Office of CPC Committee and State Council.

Li, Y. L. (2007). The Seven Reasons and Measures on the Decline of Students' Physical Fitness in China. People's Education, 7, 10-12.

Liu, Y. (2006). Who Should Assume the Responsibility of the Lack of Quality Education and Single Teaching Mode. http://sports.sina.com.cn

Lu, Z. Y., \& Yuan, X. W. (2006). First Exploration on the Decline of Students' Physical Fitness. Journal of Yichun University, 2, 139-141.

Song, Z. Z., Zhang, J. Z., Chen, H. X. et al. (2006). The Study on the Present Situation and Countermeasures of College Students' Physical Fitness. Scientific Research on Sports, $1,69-73$.

Sun, S. S., Xia, S. Y., \& Shen, Y. J. (2007). Analysis on the Physical Fitness of College Students in Chongqing. Journal of Southwest University (Pages of Natural Science), 32, 156-159.

Wang, J. L. (2015). Reflection on Problems Existing in Students' Physical Fitness Test. Sports Journal, 1, 70-74.

Zhang, G. S. The Downward Trend of Young People's Physical Fitness Level. http://www.gansu.gov.cn

Submit or recommend next manuscript to SCIRP and we will provide best service for you:

Accepting pre-submission inquiries through Email, Facebook, LinkedIn, Twitter, etc. A wide selection of journals (inclusive of 9 subjects, more than 200 journals)

Providing 24-hour high-quality service

User-friendly online submission system

Fair and swift peer-review system

Efficient typesetting and proofreading procedure

Display of the result of downloads and visits, as well as the number of cited articles

Maximum dissemination of your research work

Submit your manuscript at: http://papersubmission.scirp.org/

Or contact ape@scirp.org 